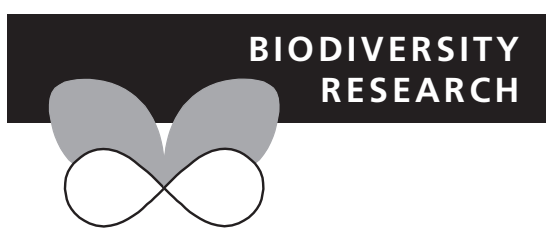

\title{
Historical legacies accumulate to shape future biodiversity in an era of rapid global change
}

\author{
Franz Essl ${ }^{1,2,3 \star}$, Stefan Dullinger ${ }^{3}$, Wolfgang Rabitsch ${ }^{2}$, Philip E. Hulme ${ }^{4}$, \\ Petr Pyšek ${ }^{5,6}$, John R. U. Wilson ${ }^{1,7}$ and David M. Richardson ${ }^{1}$
}

${ }^{1}$ Centre for Invasion Biology, Department of Botany and Zoology, Stellenbosch University, Private Bag X1, Matieland 7602, South Africa, ${ }^{2}$ Environment Agency Austria, Spittelauer Lände 5, 1090 Vienna, Austria, ${ }^{3}$ Division of Conservation Biology, Vegetation and Landscape Ecology, Faculty Centre of Biodiversity, University of Vienna, Rennweg 14, 1030 Vienna, Austria, ${ }^{4}$ The Bio-Protection Research Centre, Lincoln University, PO Box 84, Canterbury, New Zealand, ${ }^{5}$ Department of Invasion Ecology, Institute of Botany, Academy of Sciences of the Czech Republic, 252 43, Pruhonice, Czech Republic, ${ }^{6}$ Department of Ecology, Faculty of Science, Charles University in Prague, Viničná 7, 12844 Praha 2, Czech Republic, ${ }^{7}$ South African National Biodiversity Institute, Kirstenbosch Research Centre, Claremont, 7735, South Africa

${ }^{*}$ Correspondence: Franz Essl, Centre for Invasion Biology, Department of Botany and Zoology, Stellenbosch University, Private Bag X1, Matieland 7602, South Africa. E-mail: franz.essl@umweltbundesamt.at

\begin{abstract}
Aim Biodiversity responses to changing environmental forcing on species are often characterized by considerable time-lags (= relaxation times). Although changes to the occurrence and abundance of species likely have cascading effects (e.g. on species of other trophic levels, genes, community structure and ecosystem processes), current concepts addressing lagged biodiversity responses are limited to single drivers affecting a few biodiversity components (e.g. extinction debt in terms of species numbers or population size). Little attention has been paid to the interacting and cumulative nature of time-lag phenomena. Here, we synthesize current knowledge, mechanisms and implications of delayed biodiversity responses and propose a 'cumulative biodiversity lagsframework' which aims to integrate lagged responses of various components of biological organization.
\end{abstract}

Location Global.

Results Effects of change in environmental forcing are transmitted along a series of linked cause-effect relationships which act on different biodiversity components (e.g. individuals, populations, species, communities). We show that lagged responses to environmental forcing are caused by different mechanisms (e.g. metapopulation dynamics, dispersal limitation, successional dynamics), which operate sequentially on these intermediary links. Lags manifest themselves on the respective biodiversity component which changes over time; the full relaxation time of a focal system will therefore depend on the aggregate length of different lags. We elucidate key mechanisms and circumstances which are likely to cause cumulative lagged responses, and propose research avenues to improve understanding of cumulative biodiversity lags.

Main conclusions The failure to give adequate consideration to widespread cumulative time-lags often masks the full extent of biodiversity changes that have already been triggered. Effects that are particularly relevant for human livelihoods (e.g. changes in the provision of ecosystem services) may emerge with the most pronounced delay. Accordingly, the consideration of appropriate temporal scales should become a key topic in future work at the science-policy interface.

\section{Keywords}

Biological invasions, extinction debt, framework, global change, invasion debt, management, thresholds, time-lags.

\section{BIODIVERSITY DYNAMICS AND TIME-LAGS}

Humans are modifying the biosphere at a global scale. The concomitant changes increasingly impact negatively on biodiversity (Rockström et al., 2009; Butchart et al., 2010; Devictor et al., 2012), and the many services derived from ecosystems (Hooper et al., 2012; Hobbs et al., 2013). It is well known that responses to changing environmental forcing 
on species are often characterized by considerable time-lags (= relaxation times) (e.g. Tilman et al., 1994; Kuussaari et al., 2009; Essl et al., 2011; Devictor et al., 2012; Dullinger et al., 2012, 2013; Gilbert \& Levine, 2013). Such responses will likely also trigger effects on other biodiversity components (e.g. other trophic levels, genes, community structure and ecosystem processes). The possible additional delays before these subsequent accumulating effects become apparent are much less well understood (e.g. Galloway et al., 2003; Galetti et al., 2013; Svenning \& Sandel, 2013). Delays between the start of the influence of drivers of events and the unfolding of their full, complex effects can be considerable. This means that the full extent of biodiversity changes assessed at any given time might be substantially underestimated. The true cause of changes, and ecosystem degradation, may also be masked. Such cumulative effects are increasing in importance in the current era of rapid and pervasive environmental change. As a corollary, if present-day biodiversity patterns are in disequilibrium with current conditions, interventions responding to apparent drivers of change will, in many cases, be insufficient (or indeed may be entirely inappropriate) for stemming further biodiversity loss. Consequently, the capacity to understand and steer current biodiversity changes (e.g. by increasing resilience and managing risks, Seidl, 2014) may be severely compromised.

Here, we synthesize current knowledge, mechanisms and implications of what we call cumulative biodiversity lags and discuss the implications of the nature of delayed biodiversity responses.

\section{CUMULATIVE BIODIVERSITY LAGS: INTRODUCING A FRAMEWORK THAT ACCOUNTS FOR ACCUMULATING DELAYED RESPONSES}

Effects of change in environmental forcing are transmitted along a series of linked cause-effect relationships on different biodiversity components. We argue that lagged biodiversity responses are caused by different mechanisms (e.g. metapopulation dynamics, dispersal limitation, successional dynamics, soil development; Hanski \& Ovaskainen, 2002; Hylander \& Ehrlén, 2013; Svenning \& Sandel, 2013) which operate at these intermediary links. Each of these mechanisms takes its own specific and varied time to unfold. Taken together, each of them hence contributes to a cascade of lagged responses at the subsequent biodiversity components (Appendix 1).

Changes in environmental forcing will initially affect individuals of a few particular species, namely those which are most sensitive to the forcing (e.g. some plant species will respond directly to eutrophication, Fig. 1a). More specifically, the forcing will modify the fitness of the individuals directly affected (i.e. their success in passing genes to the next generation). These changes might be associated with lags, for instance due to survival of resistant life cycle stages after habitat quality change (Hylander \& Ehrlén, 2013) and will scale up to altered population dynamics thereby affecting population sizes and extent (Fig. 2a,b). If average effects on individual fitness are negative, populations will decline and might eventually be driven to local extinction. Lagged population-level responses will occur if (1) stochastic extinctions of small populations are not immediate and (2) metapopulations survive long after connectivity has decreased (if colonization-extinction dynamics are slow) (Hylander \& Ehrlén, 2013). Progressive isolation and loss of populations may finally drive species towards regional extinction. Changing environmental forcing may also have positive impacts on individual fitness of other species whose populations will consequently increase, often leading to range expansions. Again, population expansion into new geographic or ecological space will be associated with temporal delays (Jackson \& Sax, 2009; Svenning \& Sandel, 2013). The direction of response of particular species will be shaped by the interaction of their traits and niche requirements with the rate and magnitude of environmental change and the responses of populations of other species to the same forcing.

Rapid environmental change may, however, trigger further effects on biodiversity, with each subsequent change introducing additional delays (Fig. 1b,c). First, direct impacts will trigger responses of dependant species (e.g. hosts, mutualists, predators, parasites) (Fig. 2c,d). These will in turn affect other species (e.g. through competition) such that impacts on species accumulate at higher hierarchical levels of biodiversity (i.e. communities and ecosystems, Svenning \& Sandel, 2013), thereby mediating interactions between species, flows and subsequently stocks of energy and matter, and physical properties of ecosystems (Isbell et al., 2011; Hooper et al., 2012). Simultaneously, through altered selection, individuallevel impacts trickle down to lower hierarchical levels of biodiversity (e.g. genetic diversity), affecting composition and spatial structure of the gene pool (Bálint et al., 2011). The interaction of these biodiversity responses will affect ecosystem functioning, and the provision of ecosystem services (Hooper et al., 2012), with feedbacks that will affect the fitness of individuals. Finally, changes in different biodiversity components may trigger societal responses and adaptations (e.g. conservation or restoration measures), aimed at reducing or preventing negative impacts.

Thus, the full relaxation time a focal system is committed to consists of the cumulative, yet interconnected, relaxation times of the responses (Galloway et al., 2003) (Fig. 3). Attributes which modify the length of relaxation times are, for example, degree of specialization, longevity, dispersal capacity, and trophic position for species (Allendorf \& Hard, 2009; Kuussaari et al., 2009; Krauss et al., 2010; Cousins \& Vanhoenacker, 2011; Ledger et al., 2013); generation time, population size and mating system for genetic diversity (Bálint et al., 2011); and functional traits of keystone species as well as the levels of redundancy or complementarity in species interactions and ecosystem function (Schweiger et al., 2010) for community properties.

For conceptualizing this phenomenon of multiple and accumulating relaxation times, we propose the term 
F. Essl et al.

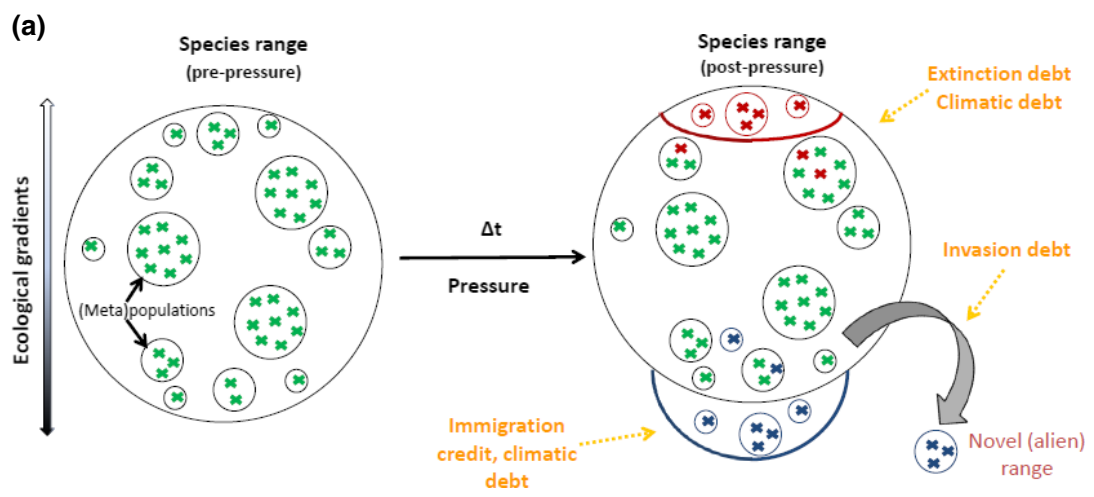

(b)

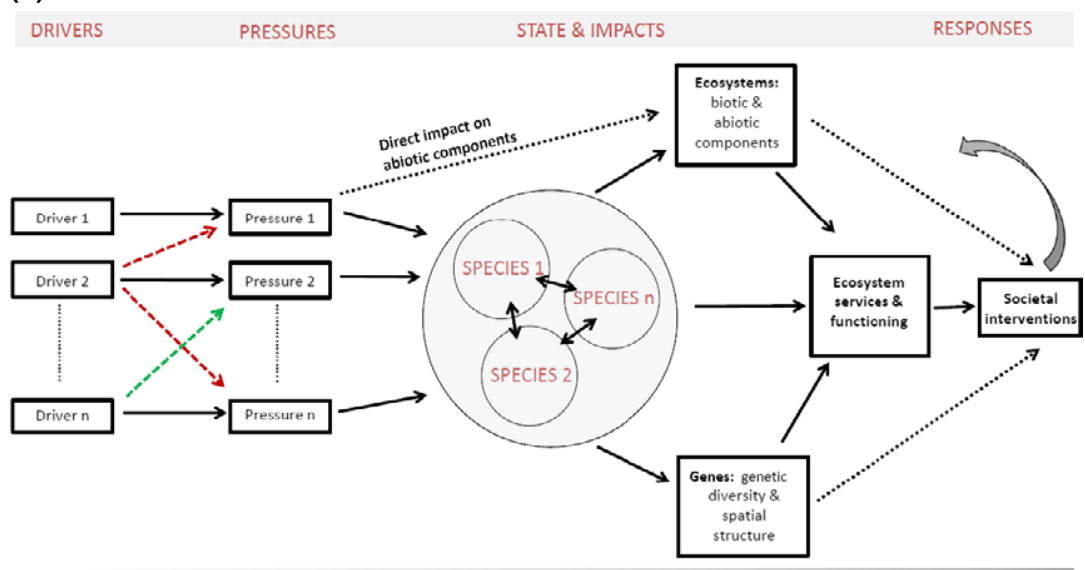

Cumulative biodiversity change

Time

(c)

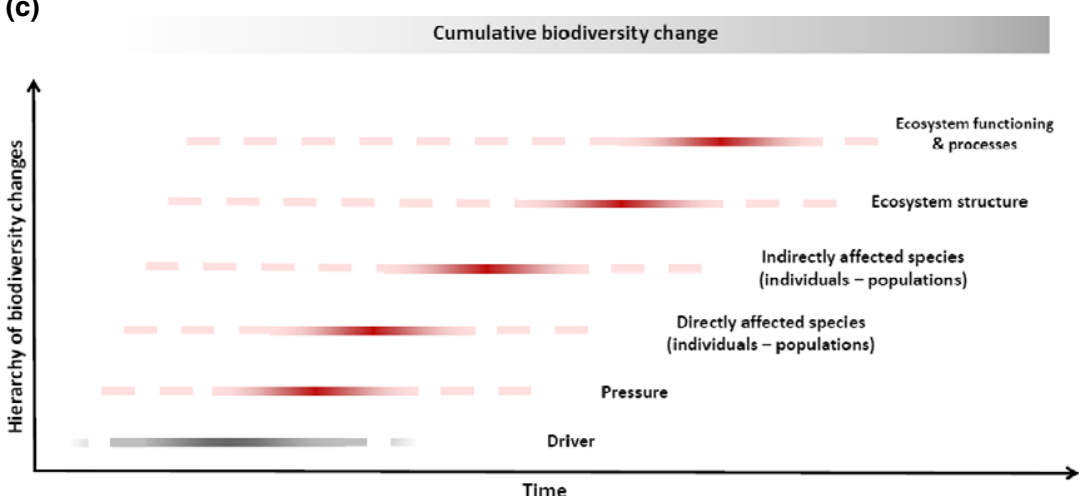

Figure 1 Conceptual model of the cumulative biodiversity lags-framework. Effects of changing environmental forcing are transmitted along cause-effect relationships (links are indicated by arrows) on biodiversity components. Responses at the level of individuals and populations are shown for a hypothetical species (in green) (a). Pressures impact first on fitness of individuals, scaling up to populations and then to the full range of the species, which may cause positive (range expansion, new populations in old range, in blue) and negative (range retraction, loss of populations in old range, in red) responses in different parts of its range across ecological gradients (e.g. climate). Impacts on species accumulate at higher (community) and, via altered selection, on lower (genetic) levels of biodiversity organization (b). Together, these changes will modify the provision of ecosystem services. Finally, changes in different biodiversity components may trigger societal responses aimed at reducing negative impacts or at increasing adaptive capacity. Lagged direct and indirect responses of different biodiversity components to pressures thus follow a hierarchy of biodiversity changes (c). Lagged responses [as shown in (a) and (b)] can occur at each of the intermediary links and will manifest themselves at the subsequent biodiversity component. Consequently, responses of biodiversity components at higher levels in the hierarchy of biodiversity responses will occur later, as they accumulate lagged responses of previous cause-effect reactions. Yellow font (a) indicates where pre-existing thematic concepts of delayed biodiversity response apply. For simplicity, feedbacks (e.g. changes to biodiversity that can result in changes to drivers) are not shown. 


\section{Extinction}

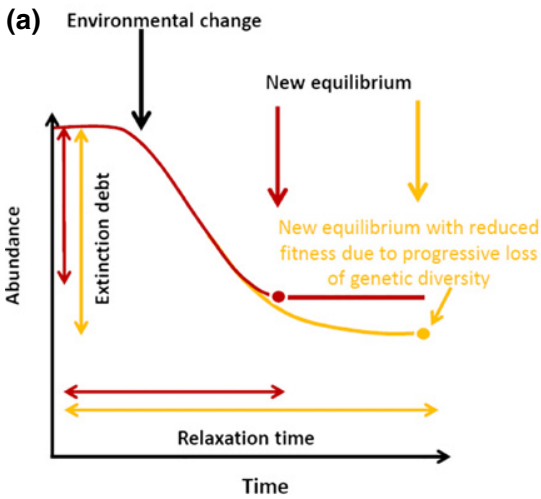

(c) Environmental change

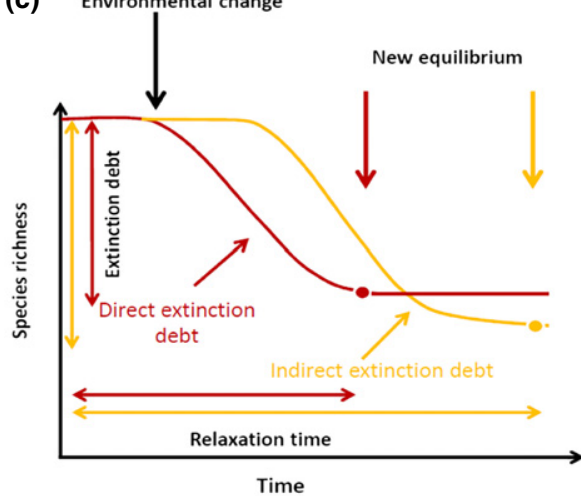

Immigration

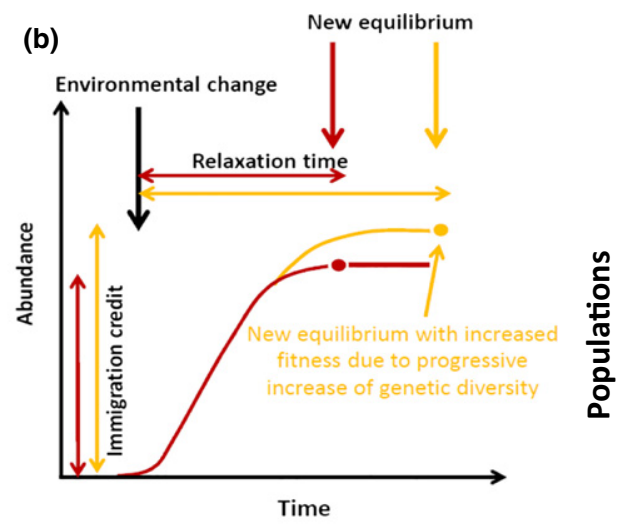

(d)

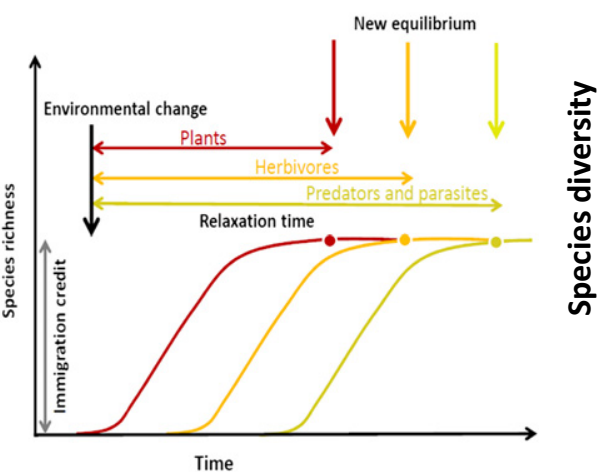

(e)
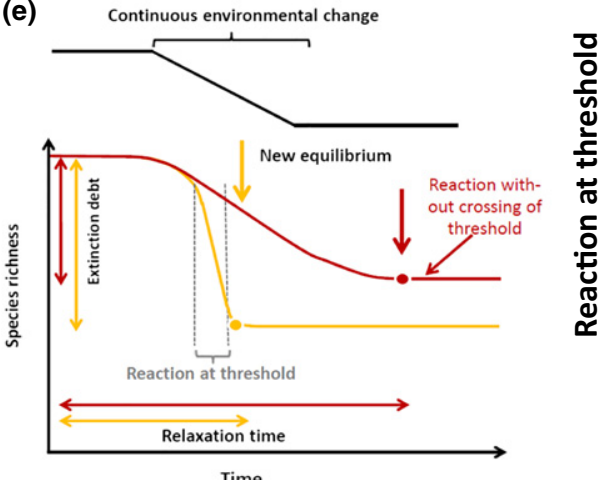

Figure 2 Mechanisms of cumulative lags in extinctions and immigration at the level of metapopulation (abundance of one focal species) and species richness within a study system. (a) At equilibrium, abundance of a species in a habitat patch is high. Following a forcing event that causes a reduction in habitat quantity or quality, a new equilibrium is reached after the extinction debt has been paid. However, if declining population size and metapopulation connectivity leads to genetic erosion, fitness may be further reduced, leading to lower abundance equilibrium and to a longer relaxation time. (b) After a new habitat patch becomes available for a focal species (e.g. through habitat restoration, succession), a new abundance equilibrium is reached after the immigration deficit has been paid off. However, if genetic diversity increases during immigration (e.g. caused by the admixing due to immigration from different sources with different gene pools,?or? evolutionary changes), fitness may be increased, leading to a higher abundance equilibrium and a longer relaxation time. (c) After a loss in habitat quantity or habitat quality, the species in the focal system directly affected by the environmental change will pay their extinction debt off until a new equilibrium is reached. Species not directly affected by the environmental change but that depend on species experiencing extinction debt will experience indirect extinction debt. This debt will only be paid when their partner species responds to the environmental forcing. Thus, indirect extinction debt will increase the full relaxation time. (d) After a new habitat patch becomes available, species of different functional groups or trophic levels will show different relaxation times. The immigration of plants is a prerequisite for the immigration of herbivores, whose presence is in turn necessary for the immigration of predators and parasites. Thus, relaxation time in the focal system increases across trophic levels. (e) After a loss in habitat quantity or habitat quality, a new abundance equilibrium is reached after the extinction debt has been paid off. However, amplifying feedbacks and the concomitant crossing of thresholds, will trigger particularly large and rapid changes, whereas above and below such thresholds, there will be relatively little changes. 


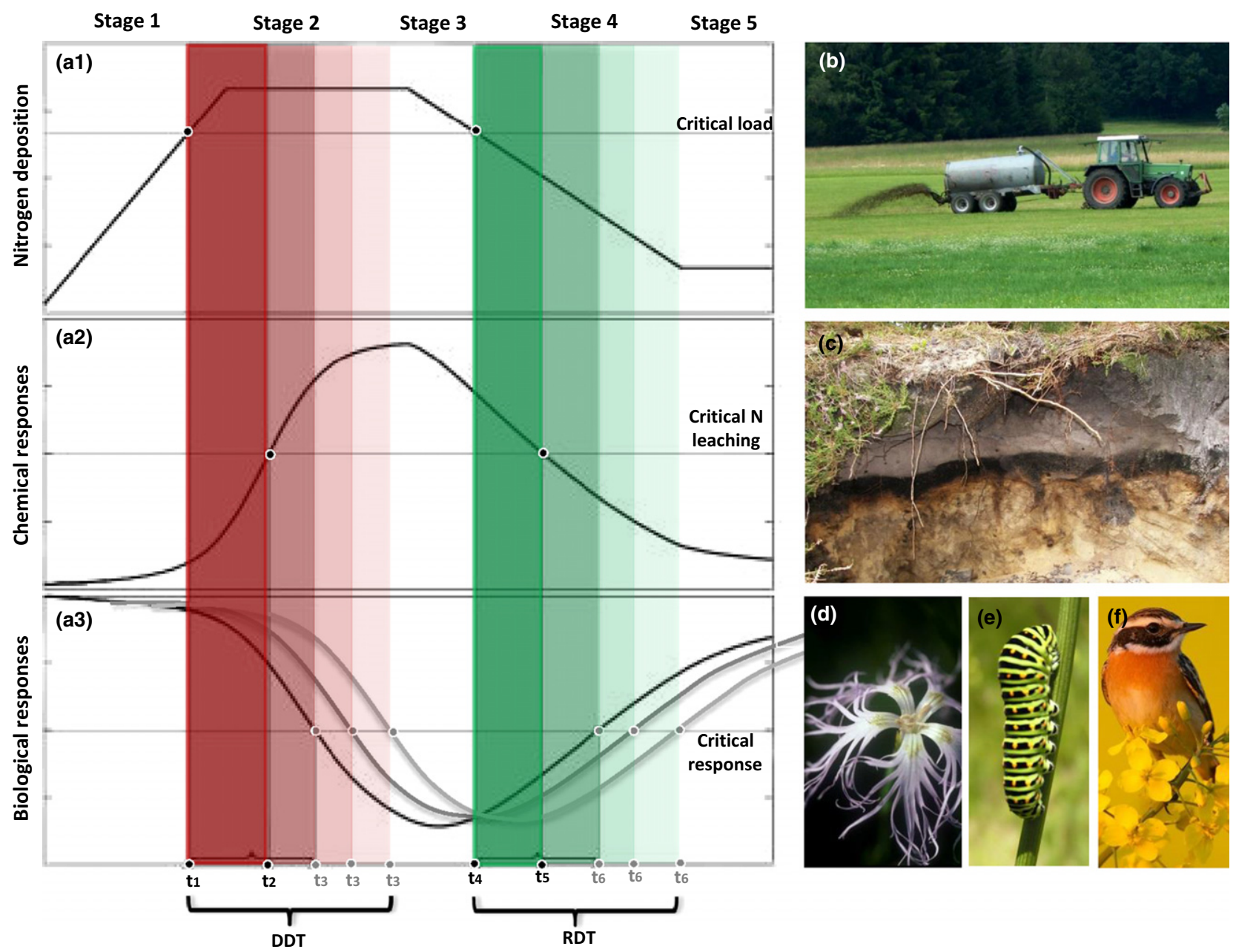

Figure 3 Schematic representation of cumulative biodiversity lags caused by eutrophication. Nitrogen deposition increases (a1, b) until it reaches a critical threshold at which point the soil nitrogen content (a2, c) starts increasing rapidly. This causes a cascade of delayed effects on the biotic components (a3) - plants (d) show a physiological response to the changes in soil chemistry (black line in a3), the change in plant tissue chemistry and plant species composition affects the herbivores (e) (dark grey line in a3) and then affect higher trophic levels (f) (light grey line in a3). This can create a time-lag between each subsequent component losing its resilience, the Damage Delay Time (DDT, red shades); and similarly once nitrogen deposition is reduced there can be delayed recovery, that is the Recovery Delay Time (RDT, green shade). Note also that functional groups can be both directly affected and indirectly affected (in this case soil organisms in particular) complicating the measurement of DDT and RDT. Modified from Posch (2003). C F. Essl (1x), Wikimedia Commons (4x).

'cumulative biodiversity lags'. We suggest linking this framework to the DPSIR conceptual model (EEA, 1999) which distinguishes root causes or ultimate drivers (D) from immediate or proximate pressures (P) (e.g. changes in biophysical processes) that affect different components of biodiversity (i.e. states, S), thereby creating impacts (I), which may trigger societal responses (R) (Fig. 1b). It thereby links the biophysical to the socio-economic sphere.

Although we argue that accumulating time-lags will prevail in many (if not most) cumulative biodiversity responses, we acknowledge that indirect effects of changing environmental forcing are not necessarily associated with increasing lag times (e.g. populations or species experiencing losses in abundance may lose dependent species in advance of full range losses). In addition, it has been shown that the removal of introduced alien herbivores on islands may lead to a quick recovery of declining native plant species (Shaw et al., 2011) and, similarly, indirect responses (e.g. changes in ecosystem structure, reduced erosion) may occur rapidly. Such rapid responses are most likely to occur when the responding biodiversity components are still present in the system, and when delaying indirect effects on the response of the focal biodiversity component (e.g. top-down feedbacks, cf. Bergstrom et al., 2009) are of little importance.

\section{Integrating pre-existing concepts of biodiversity changes}

The understanding of delayed biodiversity changes has increased rapidly over the last two decades. However, currently available concepts apply only to certain mechanisms (e.g. extinction debt) of delayed responses of one biodiversity component (e.g. spe- 
cies) in isolation. Little attention has been paid to the interacting and cumulative nature of time-lag phenomena.

The extinction debt-concept describes the likely relaxation time between a change in environmental forcing and the resultant extinction of species. When first proposed, this concept dealt with loss and fragmentation of habitats (Tilman et al., 1994), but subsequent work has expanded the pressures considered and has greatly improved the understanding of this phenomenon (e.g. Hanski \& Ovaskainen, 2002; Allendorf \& Hard, 2009; Kuussaari et al., 2009; Cousins \& Vanhoenacker, 2011; Dullinger et al., 2013; Gilbert \& Levine, 2013). In a recent conceptual development, Hylander \& Ehrlén (2013) showed that multiple processes operating on individuals and metapopulations contribute to delayed extinctions. Proven relaxation times at local scales are often in the range of decades to more than a century (Allendorf \& Hard, 2009; Kuussaari et al., 2009), especially for species near their extinction threshold and for specialized, long-lived taxa (Hanski \& Ovaskainen, 2002).

Jackson \& Sax (2009) introduced the term immigration credit for delayed species range gains and immigrations following a forcing event, and Essl et al. (2011) used the term invasion debt for a related phenomenon, that is delayed invasion of alien species into new territories. Studies of lagged responses related to alien species invasions have shown that such phenomena play a key role at all invasion stages (sensu Blackburn et al., 2011). For instance, time-lags between alien plant introduction and first record of it escaping from cultivation are on average almost 150 years for long-lived woody species in Central Europe (Kowarik, 1995) while the delay between naturalization and population expansion is often $>50$ years (Aikio et al., 2010). Finally, subsequent range filling may take many decades (Gassó et al., 2010; Svenning \& Sandel, 2013). Similarly, to describe delayed species range and abundance shifts due to changing climate, Devictor et al. (2012) coined the term climatic debt.

Interestingly, most studies only address lagged responses of biodiversity components on species. One of the few studies addressing genetic diversity is the work by Helm et al. (2009), who found evidence that changes in European land use over the past century have affected the genetic diversity of a grassland plant species (Briza media). The paucity of such studies addressing lagged responses in gene frequencies is probably because genetic change is much less immediately apparent, although some direct effects have been clearly demonstrated (Skelly et al., 2007; Richmond et al., 2009; Pauls et al., 2013), for example the evolution of smaller body size in response to size-selected harvesting (Allendorf \& Hard, 2009). Similarly, lagged responses of communities and ecosystems are particularly difficult to measure and quantify.

\section{The evidence of cumulative biodiversity lags}

Cumulative biodiversity lags unfold over long periods, especially where changes in environmental forcing are incremental (Hughes et al., 2013) or operate over long periods and at large spatial scales. Climate change provides a valuable example. Increases in energy consumption bring about rising emissions of greenhouse gases which translate, with considerable delays, into a new equilibrium of atmospheric greenhouse gas concentrations (IPCC, 2013). Major elements of the climate system respond to changing atmospheric greenhouse gas concentrations with considerable delays ranging from decades (e.g. atmospheric temperatures, precipitation, ocean acidification) to centuries (e.g. polar glaciers, sea level) (IPCC, 2013). Similarly, adjustments in species distributions and abundances track the lagged change in climatic space with further delay (Thomas et al., 2004; Loarie et al., 2009). Even the current moderate pace of climate change causes delayed range adjustments at large (Devictor et al., 2012) and small (Bertrand et al., 2012; Dullinger et al., 2012) spatial scales. Rates of range shifts that will be required in the future to track the velocity of predicted climate change are likely to be much higher (Loarie et al., 2009; but see Chen et al., 2011; Hulme, 2014). Evidence suggests that many temperate plant species were not able to fully colonize suitable habitats during the millennia following the last glaciation and population ranges are still expanding, that is the system has not yet relaxed (e.g. Svenning \& Skov, 2007). Ecosystem-level responses to changing climate will follow species range changes with further delay (Svenning \& Sandel, 2013), for instance the emergence of old-growth stands of boreal and temperate forests (including dead wood, hollow trees) needs several centuries after tree species have colonized a region (Fig. 4). As effects on communities, ecosystem properties and services often depend less on the presence of species than on their abundance (Hooper et al., 2012; Svenning \& Sandel, 2013), the consequences of delayed species responses will only become fully realized with cumulative, yet interconnected lags (Strayer et al., 2006; Hulme et al., 2013).

Changes in communities subjected to incremental environmental forcing unfold slowly, and initially, when the signal of change is small, are inherently difficult to detect (Scheffer et al., 2009; Hughes et al., 2013). For instance, the capacity of species involved in specialized mutualistic or antagonistic interactions to track forcing events is limited by the slowest responding partner. Pathogens and parasites will only be able to colonize new space after host population density or size thresholds have been reached in the new range (Keesing et al., 2010; Britton, 2013). Consequently, additional lags are to be expected for the full establishment of ecological interactions. For instance, Pyšek et al. (2011) showed that alien species in Central Europe co-opt pollinators of native flora and accumulate insect pollinators with increasing residence time. Similarly, European species introduced to North America have accumulated pathogens over centuries (Mitchell et al., 2010). Moreover, most of the substantial and increasing impacts on resident communities caused by alien species invasions world-wide (Vilà et al., 2011; Hulme et al., 2013) are density-dependent, and many, if not most, alien species have not spread to their limits in their novel ranges (Gassó 


\begin{tabular}{|c|c|c|c|c|}
\hline \multicolumn{2}{|c|}{ Equilibrium } & Immigration credit & Abundance lag & Ecosystem functioning and structure lag \\
\hline Lag times & - & Several decades to several millenia & Several decades to several centuries & c. 100 to $>1000$ years \\
\hline Mechanisms & - & $\begin{array}{l}\text { Dispersal limitation, } \\
\text { competition }\end{array}$ & $\begin{array}{c}\text { Competition, metapopulation } \\
\text { dynamics }\end{array}$ & Successional dynamics \\
\hline
\end{tabular}

(a)

(b)
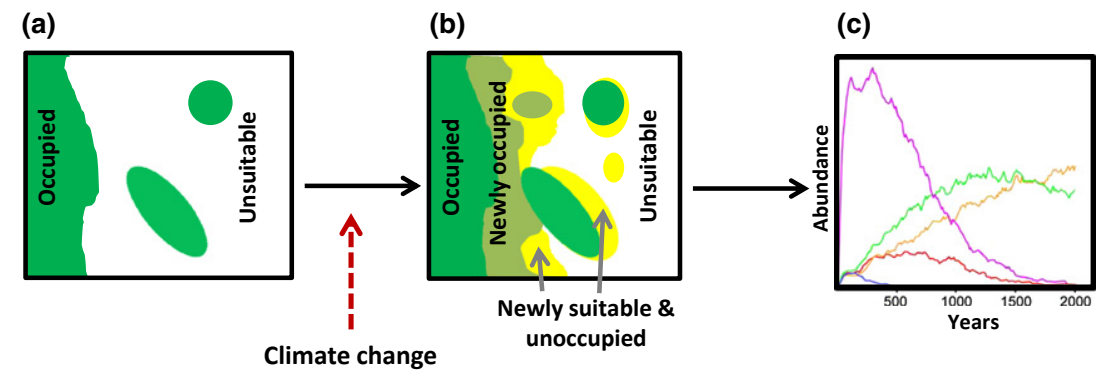

(c)

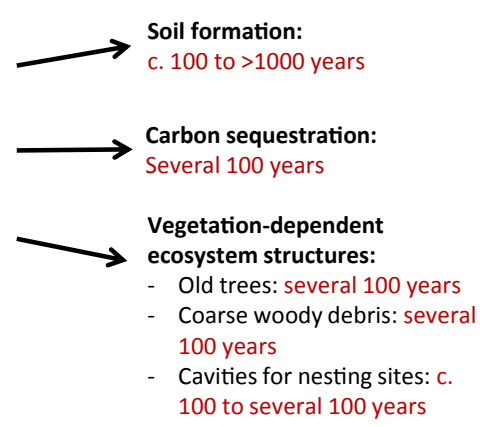

Figure 4 Schematic representation of cumulative biodiversity lags of vegetation dynamics under climate change in temperate forests (with a focus on leading range edge dynamics). Under stable climate, tree species distributions are in climatic equilibrium (a), that is all climatically suitable regions are occupied, and abundance within sites is in climatic equilibrium. Under climate change, climatically suitable regions are shifting (b). Tree species are colonizing climatically suitable regions with delay, with the large variation in lagged immigration depending mostly on the distance to source populations, species traits and interactions with the resident community. Once tree species have colonized a region, reorganizations in the abundance of tree species within the communities occur (c) (each line represents a tree species in eastern North America, Pacala et al., 1996). It may take several centuries before equilibrium is reached, as shown, for example by forest-gap models. Changes in the composition and abundance of tree species have cascading effects on ecosystem functioning (e.g. soil formation, carbon sequestration) and structure (e.g. vegetation-dependent habitat structures). Note that each biodiversity change and concomitant lag is highly dependent on the change at the preceding step in the hierarchy of change, for instance, soil formation (e.g. as a consequence of the immigration of broadleaved at the expense of conifer tree species) will only fully be triggered when tree species composition and abundance have reached equilibrium. For each stage of biodiversity change, the most important mechanisms causing lags and typical relaxation times are given. Items (a) and (b) were modified from Svenning \& Sandel (2013); data on relaxation times are taken from the same source.

et al., 2010), so the full scale of impacts is likely yet to be realized (Byers \& Goldwasser, 2001). The invasion of alien species may have positive feedbacks via interspecific facilitation on the abundance of species which had invaded the system earlier, a phenomenon termed invasional meltdown (Simberloff \& Von Holle, 1999). There is evidence that such responses do occur with substantial delays of several decades (Grosholz, 2005).

However, indirect effects of changing environmental forcing are not necessarily associated with increasing cumulative lag times. This is particularly the case when indirect responses are fully realized in advance of direct responses, and when the relaxation time of indirect responses is short compared to that for direct responses. For instance, populations or species experiencing losses in abundance will lose dependent species (e.g. co-extinction of specialist parasites, Koh et al., 2004; Dunne \& Williams, 2009) and densitydependent functional roles in ecosystems (Anderson et al., 2011) in advance of full range losses. Theoretical considerations and available evidence suggest that linked extinctions, which had been proposed as one of the main mechanisms contributing to increased extinction rates (Diamond, 1984), indeed play a prominent role (Dunn et al., 2009; Hylander \& Ehrlén, 2013), particularly for specialists (Dunn et al., 2009; Potts et al., 2010) and species at higher trophic levels
(Dunne \& Williams, 2009; Potts et al., 2010). More rarely, delayed co-extinctions may occur when the dependant species has a persistent life cycle stage, as is often the case in island vascular plants that have lost their specialized pollinators but which may still survive for decades as adult plants after reproduction has ceased (Koh et al., 2004).

\section{Regime shifts and nonlinear behaviour in complex ecological systems}

Processes in complex systems under changing conditions often exhibit nonlinear behaviour, for example, due to amplifying interacting feedback loops and multiple causalities (Stallins, 2006; Brook et al., 2008). In practical terms, this means that a small perturbation could cause a large effect, a proportional effect or no effect at all (Scheffer \& Carpenter, 2003). Such nonlinearity will mostly be restricted to specific regions or rates of change that are close to thresholds or tipping points (Hanski \& Ovaskainen, 2002; Brook et al., 2013). Often, there is a significant time-lag between the dynamics of the drivers and the expression of impacts, causing great difficulties in ecological management (Leadley et al., 2010). The importance of nonlinear behaviour should not be underestimated, and it has substantial consequences for the detection and correct assessment of changes that have already 
been triggered (Scheffer \& Carpenter, 2003; Brook et al., 2013; Hughes et al., 2013). Nonlinear behaviour in causeeffect relationships characterized by substantial lag phases means a high probability of underestimating the scale and rate of biodiversity change, even when a tipping point of an ecological system has already been crossed (Scheffer et al., 2009). The longer the lag time, the greater is the probability of underestimation and the more influential are the implications. Amplifying feedbacks and the concomitant crossing of thresholds will trigger particularly large and rapid changes (Fig. 2e). For instance, bleaching of coral reefs (i.e. corals expelling their symbiotic zooxanthellae) is a symptom of stress, and most large-scale events have been caused by temporary rises in sea water temperatures over a specific threshold (e.g. summer maxima increase of $1-2{ }^{\circ} \mathrm{C}$ for 3-4 weeks; Hoegh-Guldberg et al., 2007). As a consequence of climate change, this threshold is crossed more often. Below this tipping point, however, there is relatively little negative impact on corals. If unfavourable conditions prevail for too long, corals will die and the ecosystem will switch to a different, less complex and less species-rich stable state. Increasing ocean acidification is expected to exacerbate future coral reef endangerment as when aragonite saturation of sea water falls below 3.3 $\Omega_{\text {aragonite, carbonate accretion of corals approaches }}$ zero (Hoegh-Guldberg et al., 2007). Importantly, due to the inertia of the oceans, both sea temperature rise and aragonite saturation lag substantially behind increasing atmospheric $\mathrm{CO}_{2}$-concentrations, and the full effects of both pressures will realize only belatedly.

\section{PRIORITIES FOR RESEARCH AND SOCIETAL RESPONSES TO CUMULATIVE BIODIVERSITY LAGS}

Our current understanding of the mechanisms causing cumulative biodiversity lags is fragmentary. Empirical evidence of the scale and relevance of lagged biodiversity responses is largely limited to losses and gains in abundance and range of species, predominantly at fine spatial scales (habitats to landscapes) (Jackson \& Sax, 2009; Kuussaari et al., 2009) (Fig. 5). Most studies have examined the effect of one pressure in isolation, and there is a strong bias towards pressures which manifest themselves visually in landscapes (e.g. habitat loss, fragmentation) (Ewers \& Didham, 2006) and are thus easier to observe. Moreover, substantial biases are evident in taxonomic coverage (in favour of plants, birds and some insect groups such as butterflies), geographic distribution (temperate regions of the Northern Hemisphere) and environments (terrestrial ecosystems) (Kuussaari et al., 2009; Svenning \& Sandel, 2013). As most studies build on correlative statistical approaches, a mechanistic understanding of how observed patterns of cumulative biodiversity lags are created by ecological processes is limited.

The lack of appreciation of lagged biodiversity responses in scientific enquiry has prevented adequate integration of the implications of widespread cumulative biodiversity lags into conservation activities. For example, societal responses to environmental degradation tend to be belated and insufficient as interventions and environmental policies are modelled on changes in observed biodiversity states not on pressures. As is the case with climate change, diverse human activities have already committed biodiversity to substantial changes, the dimensions and trajectories of which will only be fully revealed in the future. This is particularly worrisome, as current conservation efforts are already judged to fall far short of curbing biodiversity loss (Butchart et al., 2010; Tittensor et al., 2014), even without considering the effect of lags. Increased efforts in creating biodiversity indicators that respond to pressures, rather than biodiversity states or human responses, are necessary to accurately monitor recent and predict forthcoming biodiversity changes (Butchart et al., 2010). More generally, the consideration of appropriate temporal scales should become a key topic in the work at the science-policy interface (e.g. IPBES, www.IPBES.net) (Perrings et al., 2011).

There is already substantial empirical evidence that the total relaxation time of a focal biodiversity component increases with the cumulative, yet interconnected relaxation lag times of the responses. As a consequence, effects that are particularly relevant for human livelihoods (e.g. changes in ecosystem structure, functioning and provision of services) (Fig. 1c) may emerge with the most pronounced delay. Models that try to assess possible future responses of species, communities and ecosystems to global change drivers need to become more closely integrated to improve the representation of cumulative lags in biodiversity dynamics and the mechanisms that may cause it. The trade-off between model complexity, uncertainties and robustness will be a major limitation of such integrated models and the accuracy of their predictions (Dukes et al., 2009; Svenning \& Sandel, 2013). Thus, sensitivity analyses and ensemble forecasts based on model families with different representations of ecological complexity and stochasticity, which have become standard tools in climate change science (Knutti \& Sedláček, 2013), should also be more widely applied for predicting biodiversity change.

We currently have only a limited causal understanding of the mechanisms and the interactions of key factors modulating lagged biodiversity responses. In particular, the interactions of species traits and environmental context (biogeography, climate, ecosystems) in shaping cumulative lags need increased scientific attention. Furthermore, driving forces differ in their character and dynamics. For example, studies analysing whether continuous incremental change or increased likelihood of pulsed events (fires, extreme climatic events, Kreyling et al., 2011) have varying effects on lag times and how velocity of change affects relaxation times are urgently needed. It is also largely unknown whether, and if so to what extent, feedbacks potentially offset or amplify cumulative lagged biodiversity responses. Although the representation of feedbacks is particularly challenging in predictive models, progress in process-based models increasingly allows for the incorporation of temporal dynamics of change. 

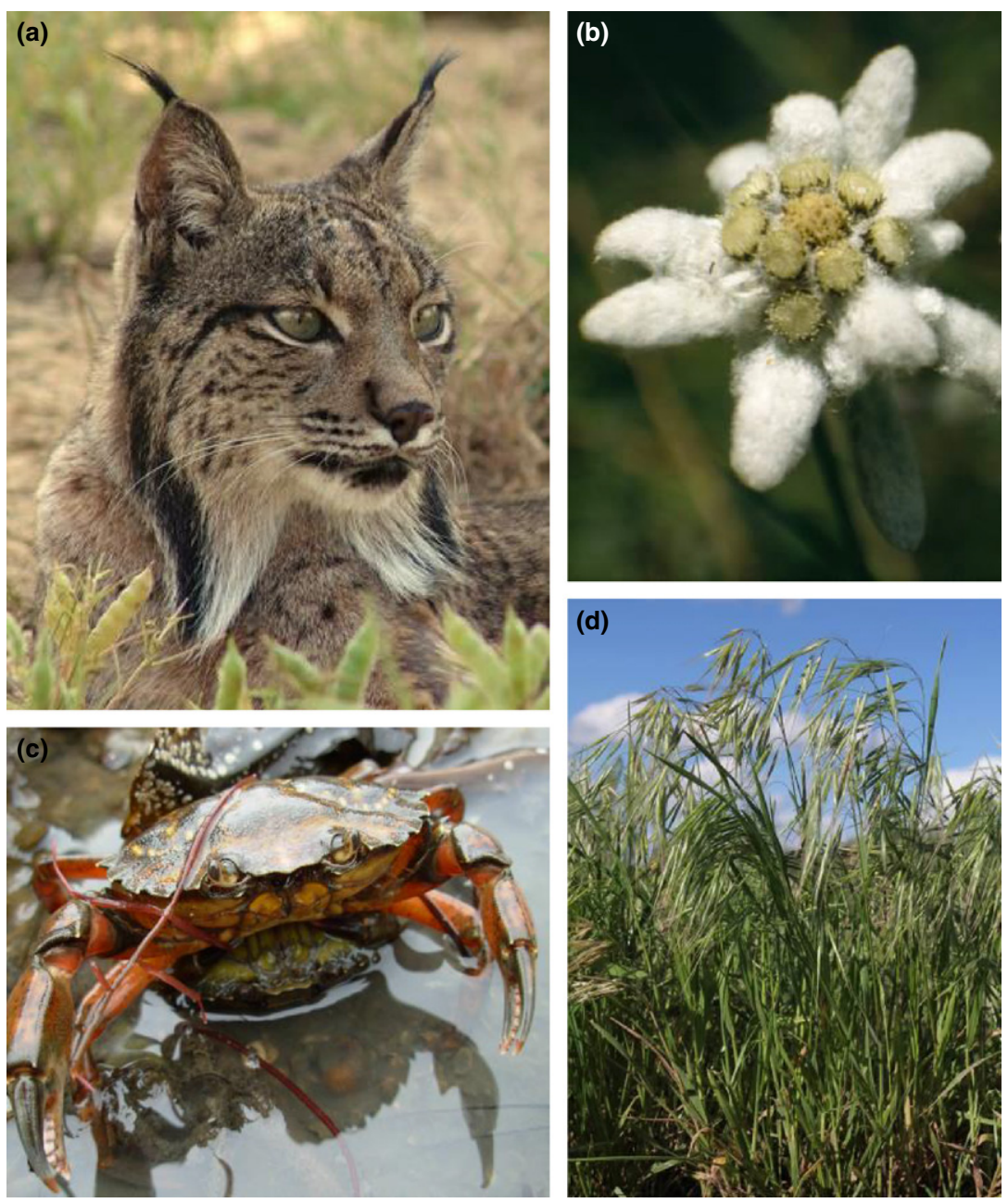

Figure 5 Examples of lagged biodiversity responses due to changing pressures. (a) Proportions of nationally Red-listed species in Europe (e.g. Iberian Lynx, Lynx pardinus) show time-lags of up to at least 100 years to changing socio-economic drivers (Dullinger et al., 2013) (extinction debt). (b) Vascular plant species of the European Alps (e.g. Leontopodium alpinum) show lagged range shifts due to climate change, especially at the receding range margin (climatic debt) (Dullinger et al., 2012). (c) The European green crab (Carcinus maenas), introduced to California in 1993, preys voraciously on native clam species. The reduction in the native clam has, over time, led to a large increase in abundance of an introduced clam species that had been rare in the first half century following the introduction of the green crab (invasion debt) (Grosholz, 2005). (d) The invasion of cheatgrass (Bromus tectorum) increases fire frequency and alters nitrogen dynamics in arid grasslands in the western USA, but the full scale of these effects only unfolded with substantial time-lags (invasion debt) (Sperry et al., 2006). (C) Programa de Conservación Ex-situ del Lince Ibérico (www.lynxexsitu.es), Harald Pauli (2x), Wikimedia Commons.

Special emphasis needs to be given to identifying critical tipping points in biodiversity responses (Fig. 2e) (Brook et al., 2013). Given the complexity and extensive data requirements of process-based models, their application will likely be limited in the near future and should be directed towards case studies which provide insights into above-mentioned key features of cumulative biodiversity lags.

Making use of already available long-term data on biodiversity and environmental conditions (including changes in magnitude of pressures), sampled with standardized protocols on many locations world-wide, for example those gathered in the global LTER-network (Redman et al., 2004) or stored in large repositories (herbaria, global biodiversity databases such as GBIF and genetic databases such as GenBank), is particularly promising. Experiments exposed to cumulative changes in pressures, nested studies addressing different scales and study systems where insights are combined from modelling, experiments and real-world data are needed to improve our understanding of patterns and processes.

\section{ENSURING A SAFE OPERATING SPACE IN AN ERA OF RAPID GLOBAL CHANGE}

Although indirect effects of changing environmental forcing are not necessarily associated with increasing cumulative lag 
times, we argue that accumulating time-lags will become increasingly common under rapid global change. For instance, Svenning \& Sandel (2013) have shown that disequilibria of vegetation dynamics under climate change will prevail in many aspects of vegetation reorganisation, that lag times often are in the range of decades to centuries, and that cascading effects are frequent.

However, there is insufficient appreciation of the importance and consequences of lagged biodiversity dynamics in an era of rapid modification of the environment. Although key features of delayed single-component biodiversity responses have enjoyed increased recognition over the past two decades, no overarching framework exists for addressing the full range of biodiversity responses. Incipient cumulative changes are easy to miss, especially in complex (eco)systems, but may be difficult or impossible to reverse later (Scheffer \& Carpenter, 2003; Hughes et al., 2013). A related concern is that society largely responds to observed losses of biodiversity instead to changes of pressures. We might not be doing enough, we might be doing it too late, and in some cases, we might even be doing completely the wrong things. This may mean many missed opportunities, as some full consequences may be avoided by early cost-effective interventions (Wearn et al., 2012).

There is no doubt that humankind has caused rapid and profound biodiversity changes which are unparalleled in ecological history and that the full extent of already triggered changes will only become expressed in the future. In all likelihood, notwithstanding that the current level of acknowledged threats to biodiversity already qualifies as the Earth's sixth mass extinction (Barnosky et al., 2011), this still is an underestimate of the biodiversity crisis and the need for action that humankind faces (Brook et al., 2008; Rockström et al., 2009; McCarthy, 2012).

\section{ACKNOWLEDGEMENTS}

FE, PP, DMR and JRUW acknowledge support from the DST-NRF Centre of Excellence for Invasion Biology. FE and SD acknowledge funding from the Austrian Climate Research Program (project K10AC1K00061 'RAG-Clim'). PP was supported by long-term research development project no. RVO 67985939 (Academy of Sciences of the Czech Republic), institutional resources of Ministry of Education, Youth and Sports of the Czech Republic, Centre of Excellence PLADIAS (project no. 14-36079G from Czech Science Foundation) and acknowledges the support by Praemium Academiae award from the Academy of Sciences of the Czech Republic. DMR received support from the South African National Research Foundation (grant 85417) and the Oppenheimer Memorial Trust. We thank Thomas Dirnböck, Bozo Frajman and Peter Schönswetter, two anonymous referees and the editor C. Kueffer for valuable comments on the paper.

\section{REFERENCES}

Aikio, S., Duncan, R.P. \& Hulme, P.E. (2010) Lag-phases in alien plant invasions: separating the facts from the artefacts. Oikos, 119, 370-378.

Allendorf, F.W. \& Hard, J.J. (2009) Human-induced evolution caused by unnatural selection through harvest of wild animals. Proceedings of the National Academy of Sciences USA, 106, 9987-9994.

Anderson, S.H., Kelly, D., Ladley, J.J., Molloy, S. \& Terry, J. (2011) Cascading effects of bird functional extinction reduce pollination and plant density. Science, 331, 1068-1071.

Bálint, M., Domisch, S., Engelhardt, C.H., Haase, P., Lehrian, S., Sauer, J., Theissinger, K., Pauls, S. \& Nowak, C. (2011) Cryptic biodiversity loss linked to global climate change. Nature Climate Change, 1, 313-318.

Barnosky, A.D., Matzke, N., Tomiya, S., Wogan, G.O.U., Swartz, B., Quental, T.B., Marshall, C., McGuire, J.L., Lindsey, E.L., Maguire, K.C., Mersey, B. \& Ferrer, E.A. (2011) Has the Earth's sixth mass extinction already arrived? Nature, 471, 51-57.

Bergstrom, D.M., Lucieer, A., Kiefer, K., Wasley, J., Belbin, L., Pedersen, T.K. \& Chown, S.L. (2009) Indirect effects of invasive species removal devastate World Heritage Island. Journal of Applied Ecology, 46, 73-81.

Bertrand, R., Lenoir, J., Piedallu, C., Riofrio-Dillon, G., de Ruffray, P., Vidal, C., Pierrat, J.-C. \& Gegout, J.-C. (2012) Changes in plant community composition lag behind climate warming in lowland forests. Nature, 479, 517-520.

Blackburn, T.M., Pyšek, P., Bacher, S., Carlton, J.T., Duncan, R.P., Jarošík, V., Wilson, J.R.U. \& Richardson, D.M. (2011) A proposed unified framework for biological invasions. Trends in Ecology and Evolution, 26, 333-339.

Britton, J.R. (2013) Introduced parasites in food webs: new species, shifting structures? Trends in Ecology and Evolution, 29, 93-99.

Brook, B.W., Sodhi, N.S. \& Bradshaw, C.J.A. (2008) Synergies among extinction drivers under global change. Trends in Ecology and Evolution, 25, 453-460.

Brook, B.W., Ellis, E.W., Perring, M.P., Mackay, A.W. \& Blomquist, L. (2013) Does the terrestrial biosphere have planetary tipping points? Trends in Ecology and Evolution, 28, 396-401.

Butchart, S.H.M., Walpole, M., Collen, B. et al. (2010) Global biodiversity: indicators of recent declines. Science, 328, 1164-1168.

Byers, J.E. \& Goldwasser, L. (2001) Exposing the mechanism and timing of impact of nonindigenous species on native species. Ecology, 82, 1330-1343.

Chen, I.C., Hill, J.K., Ohlemüller, R., Roy, D.B. \& Thomas, C.D. (2011) Rapid range shifts of species associated with high levels of climate warming. Science, 333, 1024-1026.

Cousins, S.A. \& Vanhoenacker, D. (2011) Detection of extinction debt depends on scale and specialization. Biological Conservation, 144, 782-787. 
Devictor, V., Swaay, C., Brereton, T., Brotons, L., Chamberlain, D., Heliölä, J., Herrando, S., Julliard, R., Kuussaari, M., Lindström, A., Reif, J., Roy, D.B., Schweiger, O., Settele, J., Stefanescu, C., van Strien, A., van Turnhout, C., Vermouzek, Z., WalliesDeVries, M. \& Wynhoff, I. (2012) Differences in the climatic debts of birds and butterflies at a continental scale. Nature Climate Change, 2, 121-124.

Diamond, J.M. (1984) 'Normal' extinction of isolated populations. Extinctions (ed. by M.H. Nitecki), pp. 191-246. Chicago University Press, Chicago.

Dukes, J.S., Pontius, J., Orwig, D., Garnas, J.R., Rodgers, V.L., Brazee, N., Cooke, B., Theoharides, K.A., Stange, E.E., Harrington, R., Ehrenfeld, J., Gurevitch, J., Lerdau, M., Stinson, K., Wick, R. \& Ayres, M. (2009) Responses of insect pests, pathogens, and invasive plant species to climate change in the forests of northeastern North America: what can we predict? Canadian Journal of Forest Research, 39, 231-248.

Dullinger, S., Gattringer, A., Thuiller, W. et al. (2012) Extinction debt of high-mountain plants under 21st century climate warming. Nature Climate Change, 2, 619-622.

Dullinger, S., Essl, F., Rabitsch, W., Erb, K.H., Gingrich, S., Haberl, H., Hülber, K., Jarošík, V., Krausmann, F., Kühn, I., Pergl, J., Pyšek, P. \& Hulme, P.E. (2013) Europe's other debt crisis caused by the long legacy of future extinctions. Proceedings of the National Academy of Sciences USA, 110, 7342-7347.

Dunn, R.R., Harris, N.C., Colwell, R.K., Koh, L.P. \& Sodhi, N.S. (2009) The sixth mass coextinction: are most endangered species parasites and mutualists? Proceedings of the Royal Society B, 276, 3037-3045.

Dunne, J.A. \& Williams, R.J. (2009) Cascading extinctions and community collapse in model food webs. Proceedings of the Royal Society B, 364, 1711-1723.

EEA (1999) Environmental indicators: typology and overview, Technical report no 25. European Environment Agency, Copenhagen.

Essl, F., Dullinger, S., Rabitsch, W., Hulme, P.E., Hülber, K., Jarošik, V., Kleinbauer, I., Krausmann, F., Kühn, I., Nentwig, W., Vilà, M., Genovesi, P., Gherardi, F., Desprez-Lousteau, M.-L., Roques, A. \& Pyšek, P. (2011) Socioeconomic legacy yields an invasion debt. Proceedings of the National Academy of Sciences USA, 108, 203207.

Ewers, R.M. \& Didham, R.K. (2006) Confounding factors in the detection of species responses to habitat fragmentation. Biological Reviews, 81, 117-142.

Galetti, M., Guevara, R., Cortes, M.C., Fadini, R., Van Matter, S., Leite, A.B., Labecca, F., Ribeiro, T., Carvalho, C.S., Collevatti, R.G., Pires, M.M., Guimarães, P.R., Brancalion, P.H., Ribeiro, M.C. \& Jordano, P. (2013) Functional extinction of birds drives rapid evolutionary changes in seed size. Science, 340, 1086-1090.

Galloway, J.N., Aber, J.D., Erisman, J.W., Seitzinger, S.P., Howarth, R.W., Cowling, E.B. \& Cosby, B.J. (2003) The nitrogen cascade. BioScience, 53, 341-356.
Gassó, N., Pyšek, P., Vilà, M. \& Williamson, M. (2010) Spreading to a limit: the time required for a neophyte to reach its maximum range. Diversity and Distributions, 16, 310-311.

Gilbert, B. \& Levine, J.M. (2013) Plant invasions and extinction debts. Proceedings of the National Academy of Sciences USA, 108, 1744-1749.

Grosholz, E.D. (2005) Recent biological invasion may hasten invasional meltdown by accelerating historical introductions. Proceedings of the National Academy of Sciences USA, 102, 1088-1091.

Hanski, I. \& Ovaskainen, O. (2002) Extinction debt at extinction threshold. Conservation Biology, 16, 666-673.

Helm, A., Oja, T., Saar, L., Takkis, K., Talve, T. \& Paertel, M. (2009) Human influence lowers plant genetic diversity in communities with extinction debt. Journal of Ecology, 97, 1329-1336.

Hobbs, R.J., Higgs, E. \& Hall, C. (eds) (2013) Novel ecosystems: intervening in the new ecological world order. WileyBlackwell, Oxford.

Hoegh-Guldberg, O., Mumby, P.J., Hooten, A.J., Steneck, R.S., Greenfield, P., Gomez, E., Harvell, C.D., Sale, P.F., Edwards, A.J., Caldeira, K., Knowlton, N., Eakin, C.M., Iglesias-Prieto, R., Muthiga, N., Bradbury, R.H., Dubi, A. \& Hatziolos, M.E. (2007) Coral reefs under rapid climate change and ocean acidification. Science, 318, 1737-1742.

Hooper, D.U., Adair, E.C., Cardinale, B.J., Byrnes, J.E.K., Hungate, B.A., Matulich, K.L., Gonzalez, A., Duffy, J.E., Gamfeldt, L. \& O'Connor, M.I.O. (2012) A global synthesis reveals biodiversity loss as a major driver of ecosystem change. Nature, 486, 105-108.

Hughes, T.P., Linares, C., Dakos, V., van de Leemput, I.A. \& van Nes, E.H. (2013) Living dangerously on borrowed time during slow, unrecognized regime shifts. Trends in Ecology and Evolution, 28, 149-155.

Hulme, P.E. (2014) Alien plants confront expectation of climate change impacts. Trends in Plant Science, 19, 547-549.

Hulme, P.E., Pyšek, P., Jarošik, V., Pergl, J., Schaffner, U. \& Vilá, M. (2013) Bias and error in understanding plant invasion impacts. Trends in Ecology and Evolution, 28, 212218.

Hylander, K. \& Ehrlén, J. (2013) The mechanisms causing extinction debts. Trends in Ecology and Evolution, 28, 341346.

IPCC (2013) Climate change 2013. The physical science basis. Available at: http://www.ipcc.ch/report/ar5/wg1 (accessed 1 November 2013).

Isbell, F., Calcagno, V., Hector, A., Connolly, J., Harpole, W.S., Reich, P.B., Scherer-Lorenzen, M., Schmid, B., Tilman, D., van Ruijven, J., Weigelt, A., Wilsey, B.J., Zavaleta, E.S. \& Loreau, M. (2011) High plant diversity is needed to maintain ecosystem services. Nature, 477, 199-202.

Jackson, T. \& Sax, D.F. (2009) Balancing biodiversity in a changing environment: extinction debt, immigration credit and species turnover. Trends in Ecology and Evolution, 25, 153-160. 
Keesing, F., Belden, L.K., Daszak, P., Dobson, A., Harvell, C.D., Holt, R.D., Hudson, P., Jolles, A., Jones, K.E., Michell, C.E., Myers, S.S., Bogich, T. \& Ostfeld, R.S. (2010) Impacts of biodiversity on the emergence and transmission of infectious diseases. Nature, 468, 647-652.

Knutti, R. \& Sedláček, J. (2013) Robustness and uncertainties in the new CMIP5 climate model projections. Nature Climate Change, 3, 369-373.

Koh, L.P., Dunn, R.R., Sodhi, N.S., Colwell, R.K., Proctor, H.C. \& Smith, V.S. (2004) Species coextinctions and the biodiversity crisis. Science, 305, 1632-1634.

Kowarik, I. (1995) Time lags in biological invasions with regard to the success and failure of alien species. Plant invasions - general aspects and special problems (ed. by P. Pyšek, K. Prach, M. Rejmánek and P.M. Wade), pp. 15-38. SPB Academic Publishing, Amsterdam.

Krauss, J.R., Bommarco, R., Guardiola, M., Heikkinen, R.K., Helm, A., Kuussaari, M., Lindborg, R., Ockinger, E., Pärtel, M., Pino, J., Pöyry, J., Raatikainen, K.M., Sang, A., Stefanescu, C., Teder, T., Zobel, M. \& Steffan-Dewenter, I. (2010) Habitat fragmentation causes immediate and time-delayed biodiversity loss at different trophic levels. Ecology Letters, 13, 597-605.

Kreyling, J., Jentsch, A. \& Beierkuhnlein, C. (2011) Stochastic trajectories of succession initiated by extreme climatic events. Ecology Letters, 14, 758-764.

Kuussaari, M., Bommarco, R., Heikkinen, R.K., Helm, A., Krauss, J., Lindborg, R., Öckinger, E., Pärtel, M., Pino, J., Roda, F., Stefanescu, C., Teder, T., Zobel, M. \& SteffanDewenter, I. (2009) Extinction debt: a challenge for biodiversity conservation. Trends in Ecology and Evolution, 24, 564-571.

Leadley, P., Pereira, H.M., Alkemade, R., Fernandez-Manjarrés, J.F., Proença, V., Scharlemann, J.P.W. \& Walpole, M.J. (2010) Biodiversity Scenarios: Projections of 21st century change in biodiversity and associated ecosystem services. CBD Technical Series 50.

Ledger, M.E., Brown, L.E., Edwards, L.E., Edwards, F.K., Milner, A.M. \& Woodward, G. (2013) Drought alters the structure and functioning of complex food webs. Nature Climate Change, 3, 223-227.

Loarie, S.R., Duffy, P.B., Hamilton, H., Asner, G.P., Field, C.B. \& Ackerly, D.D. (2009) The velocity of climate change. Nature, 462, 1052-1055.

McCarthy, D.P. (2012) Financial costs of meeting global biodiversity conservation targets: current spending and unmet needs. Science, 338, 946-949.

Mitchell, C.E., Blumenthal, D., Jarošík, V., Puckett, E.E. \& Pyšek, P. (2010) Controls on pathogen species richness in plants' introduced and native ranges: roles of residence time, range size, and host traits. Ecology Letters, 13, 15251535.

Pacala, S.W., Canham, C.D., Sapaonara, J., Silander, J.A., Kobe, R.K. \& Ribbens, E. (1996) Forest models defined by field measurements: estimation, error analysis, and dynamics. Eoclogical Monographs, 66, 1-43.

Pauls, S.U., Nowak, C., Bálint, M. \& Pfenninger, M. (2013) The impact of global climate change on genetic diversity within populations and species. Molecular Ecology, 22, 925946.

Perrings, C., Duraiappah, A., Larigauderie, A. \& Mooney, H. (2011) The biodiversity and ecosystem services science-policy interface. Science, 331, 1139-1140.

Posch, M. (2003) Manual for dynamic modelling of soil response to atmospheric deposition. RIVM Report 259101012/2003.

Potts, S.G., Biesmeijer, J.C., Kremen, C., Neumann, P., Schweiger, O. \& Kunin, W.E. (2010) Global pollinator declines: trends, impacts and drivers. Trends in Ecology and Evolution, 25, 345-353.

Pyšek, P., Jarošík, V., Chytrý, M., Danihelka, J., Kühn, I., Pergl, J., Tichý, L., Biesmeijer, J., Ellis, W.N., Kunin, W.E. \& Settele, J. (2011) Successful invaders co-opt pollinators of native flora and accumulate insect pollinators with increasing residence time. Ecological Monographs, 81, 277293.

Redman, C.L., Grove, J.M. \& Kuby, L.H. (2004) Integrating social science into the Long-Term Ecological Research (LTER) Network: social dimensions of ecological change and ecological dimensions of social change. Ecosystems, 7, 161-171.

Richmond, J., Reid, D.T., Ashton, K.G. \& Zamudio, K.R. (2009) Delayed genetic effects of habitat fragmentation on the ecologically specialized Florida sand skink (Plestiodon reynoldsi). Conservation Genetics, 10, 1281-1297.

Rockström, J., Steffen, W., Noone, K. et al. (2009) A safe operating space for humanity. Nature, 461, 472-475.

Scheffer, M. \& Carpenter, S.R. (2003) Catastrophic regime shifts in ecosystems: linking theory to observation. Trends in Ecology and Evolution, 18, 648-656.

Scheffer, M., Bascompte, J., Brock, W.A., Brovkin, V., Carpenter, S.R., Dakos, V., Held, H., van Nes, E.H., Rietkerk, M. \& Sugihara, G. (2009) Early-warning signals for critical transitions. Nature, 461, 53-59.

Schweiger, O., Biesmeijer, J.C., Bommarco, R. et al. (2010) Multiple stressors on biotic interactions: how climate change and alien species interact to affect pollination. Biological Reviews, 85, 777-795.

Seidl, R. (2014) The shape of ecosystem management to come: anticipating risks and fostering resilience. BioScience, 64, 1159-1169.

Shaw, J., Terauds, A. \& Bergstrom, D. (2011) Rapid commencement of ecosystem recovery following aerial baiting on sub-Antarctic Macquarie Island. Ecological Management and Restoration, 12, 241-244.

Simberloff, D. \& Von Holle, B. (1999) Positive interactions of nonindigenous species: invasional meltdown? Biological Invasions, 1, 21-32. 
Skelly, D.K., Shaw, R.G. \& Etterson, J.R. (2007) Evolutionary responses to climate change. Conservation Biology, 21, 1353-1355.

Sperry, L.J., Belnap, J. \& Evans, R.D. (2006) Bromus tectorum invasion alters nitrogen dynamics in an undisturbed arid grassland ecosystem. Ecology, 87, 603-615.

Stallins, J.A. (2006) Geomorphology and ecology: unifying themes for complex systems in biogeomorphology. Geomorphology, 77, 207-216.

Strayer, D.L., Eviner, V.T., Jeschke, J.M. \& Pace, M.L. (2006) Understanding the long-term effects of species invasions. Trends in Ecology and Evolution, 21, 645-651.

Svenning, J.C. \& Sandel, B. (2013) Disequilibrium vegetation dynamics under future climate change. American Journal of Botany, 100, 1266-1286.

Svenning, J.C. \& Skov, F. (2007) Could the tree diversity pattern in Europe be generated by postglacial dispersal limitation? Ecology Letters, 10, 453-460.

Thomas, C.D., Cameron, A., Green, R.E., Bakkenes, M., Beaumont, L.J., Collingham, Y.C., Erasmus, B.F.N., de Siqueira, M.F., Grainger, A., Hannah, L., Hughes, L., Huntley, B., van Jaarsveld, A.S., Midgley, G.F., Miles, L., Ortega-Huerta, M.A., Peterson, A.T., Phillips, O.L. \& Williams, S.E. (2004) Extinction risk from climate change. Nature, 427, 145-148.

Tilman, D., May, R.M., Lehman, C.L. \& Nowak, M.A. (1994) Habitat destruction and the extinction debt. Nature, 371, 65-66.

Tittensor, D.P., Walpole, M., Hill, S.L.L. et al. (2014) A midterm analysis of progress towards international biodiversity targets. Science, 346, 241-244.

Vilà, M., Espinar, J.L., Hejda, M., Hulme, P.E., Jarošík, V., Maron, J.L., Pergl, J., Schaffner, U., Sun, Y. \& Pyšek, P. (2011) Ecological impacts of invasive alien plants: a metaanalysis of their effects on species, communities and ecosystems. Ecology Letters, 14, 702-708.

Wearn, O., Reumann, D.C. \& Ewers, R.M. (2012) Extinction debt and windows of conservation opportunity in the Brazilian Amazon. Science, 337, 228-232.

\section{APPENDIX 1 \\ GLOSSARY OF KEY TERMS RELEVANT FOR THE CUMULATIVE BIODIVERSITY LAGS-FRAME- WORK}

\section{Biodiversity component}

This term includes the biotic elements (e.g. gene pool, population, species, communities, ecosystems), processes (e.g. species interactions and interaction networks) and the biophysical attributes (e.g. functioning and structure of ecosystems, ecosystem services) of a focal ecological system.

\section{Biodiversity hierarchy}

The three levels of biodiversity organization, i.e. genetic, species and ecosystem diversity.

\section{Ecosystem services}

Ecosystem resources and processes that provide benefits and values to humans.

\section{Equilibrium state}

Also known as stable state where rates of losses and gains of system elements (e.g. species) balance each other and there is hence no longer term increasing or decreasing trend (e.g. in species richness or service provision rate).

\section{Extinction debt}

The number or proportion of species of a community expected to eventually become extinct as the community reaches a new equilibrium after a forcing event or under an incremental environmental change such as habitat destruction, eutrophication or habitat fragmentation.

\section{Fitness}

A measure of reproductive success of an organism in passing its genes to the next generation.

\section{Immigration credit}

The number of species committed to eventual immigration following a forcing event because of suitable environment and opportunity.

\section{Invasion debt}

A concept that posits that even if introductions of alien species to a territory cease (and/or other drivers of invasion are relaxed, for example propagule pressure is reduced), new invasions will continue to emerge and already-alien species will continue to spread and cause potentially greater impacts, because large numbers of potentially invasive alien species are already present.

\section{Relaxation time}

The time elapsed between the onset of changed environmental pressures and the moment the new equilibrium is reached. More or less extensive relaxation times may occur at all levels of the biodiversity hierarchy including attributes or effects of biodiversity like functional diversity or ecosystem service provision.

\section{Threshold}

Specific rate or level of change in a focal system causing strong qualitative or quantitative responses. Crossing such thresholds will cause a system to shift to novel stable system states rapidly. 


\section{BIOSKETCH}

Franz Essl is an ecologist at the University of Vienna and the Austrian Environment Agency and is a Research Associate at the DST-NRF Centre of Excellence for Invasion Biology (http://academic.sun.ac.za/cib/). $\mathrm{He}$ is interested in causes and patterns of biological invasions, in the processes governing diversity patterns of species and habitats, and in the impact of climate change on the distribution of biota and the resulting consequences for nature conservation.

Author contributions: F.E. conceived the ideas and led the writing, all authors contributed substantially to the writing.

Editor: Christoph Kueffer 